\author{
Halina GARBALIŃSKA ${ }^{1}$ \\ Bartłomiej MAJKOWSKI ${ }^{2}$
}

\title{
POMIARY SORPCYJNE WSPÓŁCZYNNIKA DYFUZJI WILGOCI RÓŻNEGO RODZAJU ZAPRAW
}

\begin{abstract}
W referacie przedstawiono możliwość wykorzystania niestacjonarnych pomiarów sorpcyjnych do określenia współczynnika dyfuzji $D_{m}$ porowatych materiałów budowlanych. Badaniami objęto trzy różne zaprawy: cementową, cementowowapienną i modyfikowaną. Eksperyment zrealizowano w 18 klimatach - przy trzech temperaturach: $5,20,35^{\circ} \mathrm{C}$ i przy sześciu poziomach wilgotności względnej powietrza $\varphi$. Na podstawie uzyskanych wyników badań sorpcyjnych wyznaczano dla poszczególnych zapraw wartości współczynnika dyfuzji wilgoci odpowiadające różnym temperaturom i różnym poziomom sorpcyjnego zawilgocenia. Przedstawione w referacie obliczenia współczynników dyfuzji $D_{m}$ bazowały na procedurach typu $\sqrt{ }_{t}$ i typu logarytmicznego. Otrzymane rezultaty pozwoliły ocenić użyteczność obydwu procedur w odniesieniu do testowanych materiałów. We wszystkich cyklach i w przypadku każdej z zapraw uzyskiwano zbliżone wartości współczynników $D_{m}(\sqrt{ } t)$ i $D_{m}(\ln )$, co pozwala rekomendować obydwie procedury jako porównywalne. Przeprowadzone badania pozwoliły ponadto ocenić wpływ zawartości wilgoci na wielkość współczynników dyfuzji. Stwierdzono występowanie jednoznacznej tendencji w odniesieniu do każdej temperatury i każdej z badanych zapraw. Zaobserwowano wzrost wartości $D_{m}$ wraz ze zwiększaniem się wilgotności względnej do poziomu 50\%. Dla tego poziomu zawilgocenia materiału współczynnik dyfuzji osiągał wartość maksymalną. Następnie wartość tego współczynnika spadała stopniowo w miarę wzrostu wilgotności. Stwierdzono, że w najszerszym zakresie wilgotności, tj. przy $\varphi \approx 96 \%$ współczynniki dyfuzji osiągają wartość minimalną, odpowiadającą zakresowi najniższych wilgotności. Przeprowadzone badania pozwoliły ocenić nie tylko wpływ wilgotności, ale także wpływ temperatury na wyznaczane współczynniki dyfuzji. Obydwie zastosowane metody wykazały znaczący wpływ tego czynnika na wyznaczane wartości współczynników dyfuzji $D_{m}$.
\end{abstract}

Słowa kluczowe: sorpcja, dyfuzja wilgoci, współczynnik dyfuzji, zaprawa, materiał porowaty

\footnotetext{
${ }^{1}$ Autor do korespondencji: Halina Garbalińska, Zachodniopomorski Uniwersytet Technologiczny w Szczecinie, al. Piastów 50, 70-311 Szczecin, 91-449-48-29, Halina.Garbalinska@ zut.edu.pl

${ }^{2}$ Doktorant Bartłomiej Majkowski, Zachodniopomorski Uniwersytet Technologiczny w Szczecinie, al. Piastów 50, 70-311 Szczecin, 91-449-48-29, Bartlomiej.Majkowski@ zut.edu.pl
} 


\section{Wprowadzenie}

Typowe materiały budowlane takie jak cegła, beton, zaprawy charakteryzują się strukturą kapilarno-porowatą. Zjawiska transportu wilgoci zachodzące w tych materiałach składają się na bardzo skomplikowany proces. Związane jest to ze złożoną strukturą porowatości w materiałach tego typu, jak również z występowaniem rozmaitych mechanizmów transportu wilgoci, takich jak: dyfuzja, przepływ laminarny, błonkowy, kapilarny, których współudział w globalnym strumieniu wilgoci często zmienia się bardzo znacząco $\mathrm{w}$ trakcie trwania procesu, np. wysychania lub nawilżania [1]. W ujęciu fenomenologicznym proces transportu wilgoci w materiale porowatym w zakresie wilgotności sorpcyjnej opisany jest przez współczynnik dyfuzji wilgoci. Współczynnik ten może być wyznaczony z zadowalającą dokładnością jedynie na drodze doświadczalnej [6]. Stanowi on parametr materiałowy, w którym znajduje swój ilościowy wyraz intensywność procesu migracji wilgoci. Przy czym w zależności od wilgotności materiału i stanu wilgotnościowego powietrza w jego bezpośrednim otoczeniu, molekuły wody mogą wnikać w głąb materiału w wyniku procesu sorpcji, albo wędrować $\mathrm{w}$ kierunku otoczenia $\mathrm{w}$ wyniku procesu desorpcji [1]. W artykule przedstawiono próbę wykorzystania zadania odwrotnego [7], bazującego na zarejestrowanym przebiegu procesu sorpcji, do wyznaczenia współczynnika $D_{m}$ trzech materiałów budowlanych. Eksperyment zrealizowany został w trzech temperaturach $T$ i sześciu zakresach wilgotności względnej powietrza $\Delta \varphi$. Do wyznaczenia $D_{m}$ wykorzystano dwie różne procedury obliczeniowe: metodę typu $\sqrt{ } t$ - odnoszącą się w swoich założeniach teoretycznych do fazy początkowej procesu [2] oraz metodę logarytmiczną - dotyczącą jego zaawansowanej fazy [3].

\section{Opis badań}

Do testowania przydatności niestacjonarnej techniki sorpcyjnej wybrano trzy popularne rodzaje zapraw budowlanych - cementową (ZC), modyfikowaną (ZM) oraz cementowo-wapienną (ZCW). Eksperyment objął zakres dodatnich temperatur $\left(T=5^{\circ} \mathrm{C}, 20^{\circ} \mathrm{C}, 35^{\circ} \mathrm{C}\right)$, jakie realnie mogą wystąpić w przeciętnych warunkach budowlanych. Badania w każdej temperaturze realizowano przy sześciu poziomach wilgotności $\varphi$, pokrywających niemal cały zakres wilgotności sorpcyjnej (od $\varphi \approx 11 \%$ do $\varphi \approx 98 \%$ ).

Eksperyment polegał na wycięciu równoległościennych próbek o grubości $1 \mathrm{~cm}$, następnie zaizolowaniu ich na pobocznicach i umieszczeniu w atmosferze o stałej temperaturze i niezmiennej wilgotności. Wymiana wilgoci między próbką a otoczeniem odbywała się przez dwie powierzchnie czołowe. Próbki w trakcie badań sorpcji przechowywane były w szczelnych pojemnikach o stałej wilgotności oraz w komorach termostatycznych o stałej temperaturze. Dla utrzymania niezmiennej wilgotności względnej powietrza próbki umieszczono 
w atmosferze nad nasyconymi roztworami następujących soli: $\mathrm{LiCl}(\varphi \approx 11 \%)$, $\mathrm{MgCl}_{2}(\varphi \approx 32 \div 34 \%), \operatorname{Mg}\left(\mathrm{NO}_{3}\right)_{2},(\varphi \approx 50 \div 59 \%), \mathrm{NaCl}(\varphi \approx 75 \div 76 \%), \mathrm{KCl}(\varphi \approx$ $83 \div 88 \%), \mathrm{K}_{2} \mathrm{SO}_{4}(\varphi \approx 96 \div 98 \%)$. W zależności od zadanej temperatury wilgotność $\mathrm{w}$ szczelnych pojemnikach z różnymi roztworami wykazywała różnice rzędu kilku procent.

Istota pomiarów polegała na rejestracji zmieniającej się masy próbki aż do momentu jej ustabilizowania się. Odstępy między badaniami wynoszące początkowo 6, 8, 12 godzin wydłużono z czasem do 7 dni. Na początku bowiem przyrosty masy były wyraźne, a w miarę zbliżania się do równowagi sorpcyjnej stawały się coraz wolniejsze. Pomiary zmieniającej się masy próbki wykonywane były za pomocą wagi laboratoryjnej o dokładności 1mg.

Przed rozpoczęciem zasadniczego eksperymentu próbki wysuszono do stałej masy, a następnie poddawano procesom sorpcji. Realizowane były one w trzech temperaturach: $5^{\circ} \mathrm{C}, 20^{\circ} \mathrm{C}, 35^{\circ} \mathrm{C}$, przy czym każdorazowo badania dotyczyły sześciu coraz to szerszych zakresów wilgotności względnej: $\varphi \approx 0 \%$ $\rightarrow \varphi \approx 11 \%, \varphi \approx 0 \% \rightarrow \varphi \approx 32 \div 34 \%, \varphi \approx 0 \% \rightarrow \varphi \approx 50 \div 59 \%, \varphi \approx 0 \% \rightarrow \varphi \approx$ $75 \div 76 \%, \varphi \approx 0 \% \rightarrow \varphi \approx 75 \div 76 \%, \varphi \approx 0 \% \rightarrow \varphi \approx 75 \div 76 \%$.

$\mathrm{W}$ założonych w eksperymencie 18 klimatach poddano badaniom sorpcyjnym łącznie 162 próbki. Na podstawie zebranych wyników obliczono dla poszczególnych materiałów wartości współczynników dyfuzji wilgoci odpowiadające różnym temperaturom i różnym poziomom wilgotności.

\section{Współczynnik dyfuzji wilgoci}

Współczynnik dyfuzji wilgoci $D_{m}$ może być wyznaczany w pomiarach stacjonarnych bądź niestacjonarnych. W niniejszym artykule przedyskutowano możliwość wykorzystania niestacjonarnej techniki pomiarowej opartej na pomiarach sorpcji, a bazującej na dwóch niezależnych procedurach obliczeniowych. Parametr $D_{m}$ wyznaczono korzystając z reguły typu $\bigvee_{t}$ oraz reguły logarytmicznej. Procedury te odniesione zostały do trzech testowanych materiałów (ZC, ZM, ZCW), które przebadano w trzech wytypowanych temperaturach oraz sześciu ściśle ustalonych poziomach wilgotności powietrza.

$\mathrm{W}$ obliczeniach posłużono się wzorami zaproponowanymi w [1]:

- dla procedury $\sqrt{ } t$ :

$$
\begin{aligned}
& D_{m}=a_{\sqrt{t}}^{2} \frac{\pi d^{2}}{16 \Delta m_{\max }^{2}} \\
& a_{\sqrt{t}}=\frac{\Delta m_{t}}{\sqrt{t}}
\end{aligned}
$$


- dla procedury logarytmicznej:

$$
\begin{aligned}
& D_{m}=-a_{l n} \frac{d^{2}}{\pi^{2}} \\
& a_{l n}=\frac{\ln \left(1-\frac{\Delta m_{t}}{\Delta m_{\max }}\right)+0,21}{t}
\end{aligned}
$$

gdzie: $\quad D_{m}-$ współczynnik dyfuzji wilgoci $\left[\mathrm{m}^{2} / \mathrm{h}\right]$;

$a_{\sqrt{ }}, a_{\mathrm{ln}}-$ współczynniki kierunkowe $\left[\mathrm{g} / \mathrm{h}^{0,5}\right],[1 / \mathrm{h}]$;

$d$ - grubość próbki $[\mathrm{m}]$;

$\Delta m_{t}-$ zmiana masy po czasie $t[\mathrm{~g}]$;

$\Delta m_{\max }-$ całkowita zmiana masy [g];

$t$ - czas $[\mathrm{h}]$.

Sporządzone odwzorowania funkcji $\Delta m_{t}=\mathrm{f}(\sqrt{ } t)$ oraz $\ln \left(1-\Delta m_{\mathrm{t}} / \Delta m_{\max }\right)=\mathrm{f}(t)$ dla poszczególnych próbek stanowiły podstawę do wyznaczenia współczynników kierunkowych w odniesieniu do uzyskanych 324 pojedynczych wykresów. Na wykresach odwzorowujących przebieg funkcji $\Delta m_{t}=\mathrm{f}(\sqrt{ } t)$ ustalano odcinek (przypisany fazie początkowej procesu), cechujący się prostoliniowym przebiegiem i wyznaczano odpowiadający mu współczynnik kierunkowy $a_{\sqrt{ } t}$. Z kolei $\mathrm{z}$ wykresów przedstawiających przebieg funkcji logarytmicznej $\ln \left(1-\Delta m_{t} / \Delta m_{\max }\right)$ $=\mathrm{f}(t)$ sczytywano odcinek (przypisany fazie zaawansowanej badanego procesu sorpcji) cechujący się prostoliniowym przebiegiem i wyznaczano odpowiadający mu współczynnik $a_{\mathrm{ln}}$. Dysponując współczynnikami kierunkowymi wyznaczonymi oddzielnie dla każdej próbki o grubości $d$, obliczano współczynnik dyfuzji przy zastosowaniu niezależnie każdej z reguł, czyli ustalano wartości $D_{m}(\sqrt{ } t)$ i $D_{m}(\ln )$. Dla poszczególnych zakresów $\Delta \varphi$ określano następnie średnią arytmetyczną $D_{m}(\sqrt{ } t)$ oraz $D_{m}(\ln )$, na podstawie wyników uzyskanych w danym pomiarze na trzech próbkach każdego z badanych materiałów, analogicznie jak w pracy [5].

\section{Uzyskane wyniki}

Dla zilustrowania podstaw obydwu procedur przedstawiono na rysunkach $1 \div 6$ przykładowe wypadkowe wykresy dotyczące trzech badanych zapraw, a odwzorowane w poszczególnych temperaturach $T=5,20,35^{\circ} \mathrm{C}$ w odniesieniu do zakresu wilgotności $\Delta \varphi \approx 0 \rightarrow 50 \div 59 \%$. 


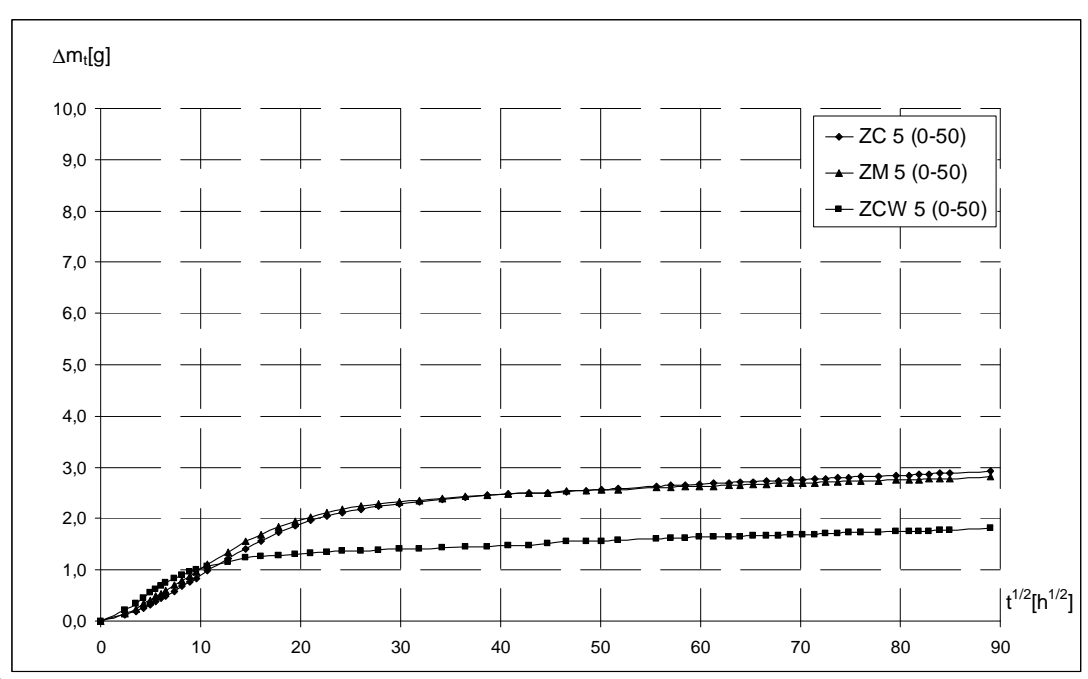

Rys. 1. Wypadkowe przebiegi $\Delta m_{t}=\mathrm{f}(\sqrt{ } t)$ dla zaprawy cementowej, zaprawy modyfikowanej oraz cementowo-wapiennej w $T=5^{\circ} \mathrm{C}$ oraz $\varphi=0 \% \rightarrow 59 \%$

Fig. 1. Graph of function $\Delta m_{t}=\mathrm{f}(\sqrt{ } t)$ for cement mortar, modified mortar and cementlime mortar at $T=5^{\circ} \mathrm{C}$ and $\varphi=0 \% \rightarrow 59 \%$

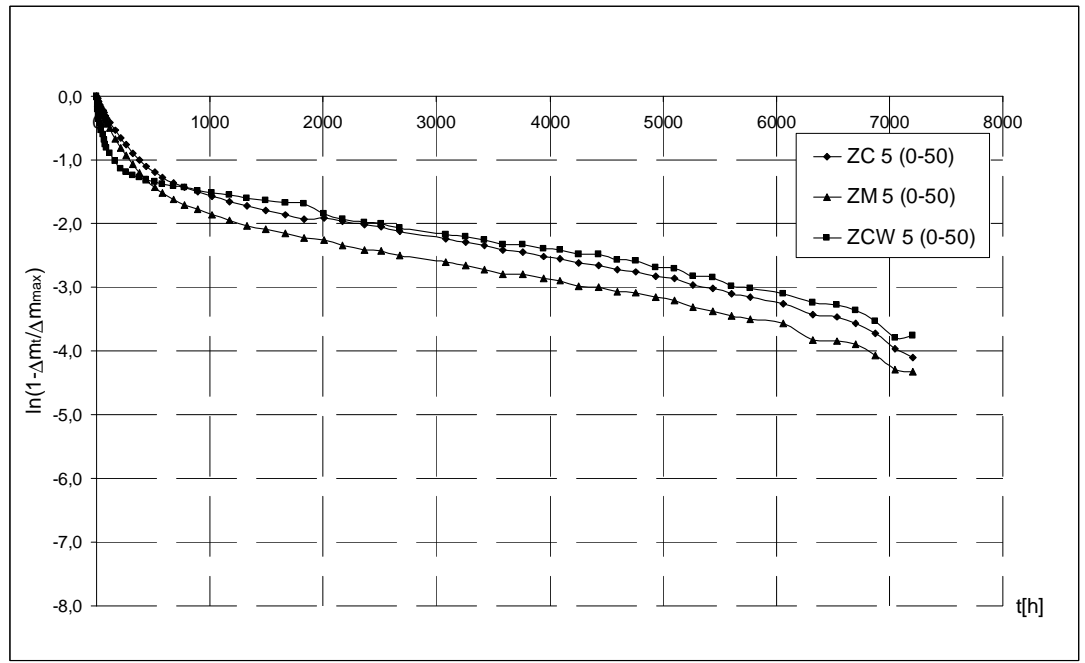

Rys. 2. Wypadkowe przebiegi $\ln \left(1-\Delta m_{t} / \Delta m_{\max }\right)=\mathrm{f}(t)$ dla zaprawy cementowej, zaprawy modyfikowanej oraz cementowo-wapiennej w $T=5^{\circ} \mathrm{C}$ oraz $\varphi=0 \% \rightarrow 59 \%$

Fig. 2. Graph of function $\ln \left(1-\Delta m_{t} / \Delta m_{\max }\right)=\mathrm{f}(t)$ for cement mortar, modified mortar and cement-lime mortar at $T=5^{\circ} \mathrm{C}$ and $\varphi=0 \% \rightarrow 59 \%$ 


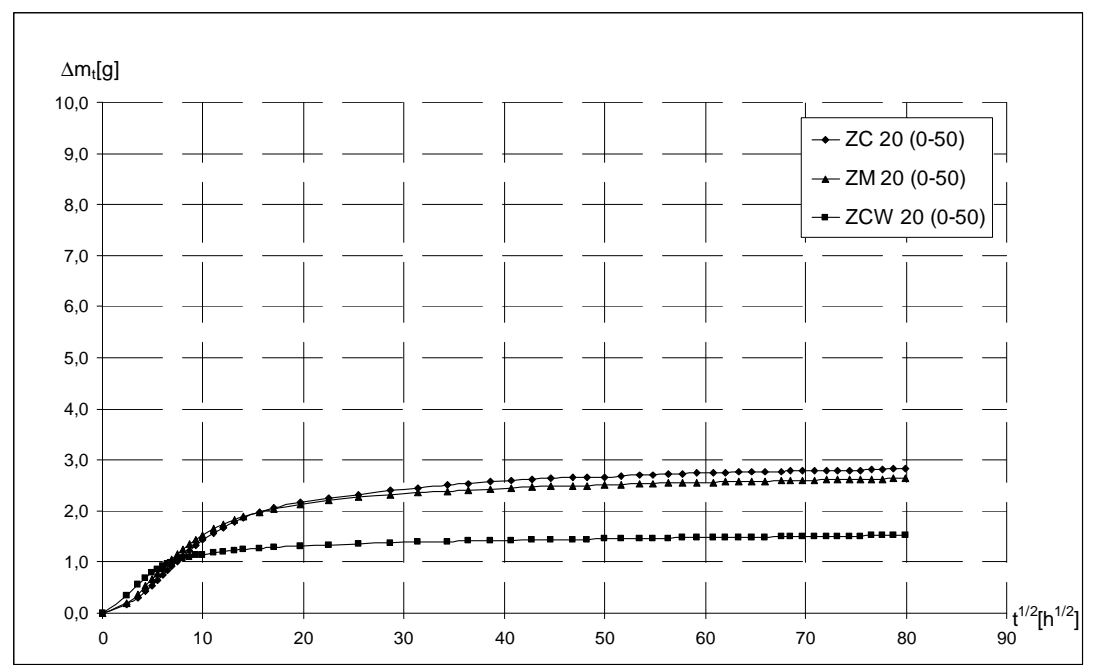

Rys. 3. Wypadkowe przebiegi $\Delta m_{t}=\mathrm{f}(\sqrt{ } t)$ dla zaprawy cementowej, zaprawy modyfikowanej oraz cementowo-wapiennej w $T=20^{\circ} \mathrm{C}$ oraz $\varphi=0 \% \rightarrow 54 \%$

Fig. 3 Graph of function $\Delta m_{t}=\mathrm{f}(\sqrt{ } t)$ for cement mortar, modified mortar and cementlime mortar at $T=20^{\circ} \mathrm{C}$ and $\varphi=0 \% \rightarrow 54 \%$

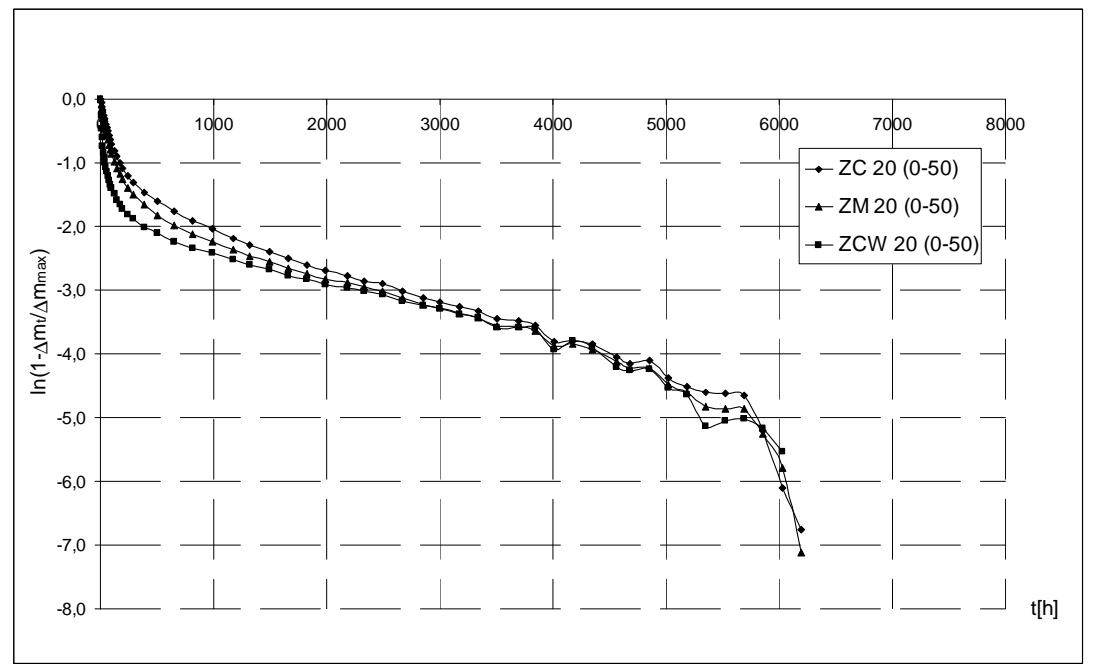

Rys. 4. Wypadkowe przebiegi $\ln \left(1-\Delta m_{t} / \Delta m_{\max }\right)=\mathrm{f}(t)$ dla zaprawy cementowej, zaprawy modyfikowanej oraz cementowo-wapiennej w $T=20^{\circ} \mathrm{C}$ oraz $\varphi=0 \% \rightarrow 54 \%$

Fig. 4. Graph of function $\ln \left(1-\Delta m_{t} / \Delta \mathrm{m}_{\max }\right)=\mathrm{f}(t)$ for cement mortar, modified mortar and cement-lime mortar at $T=20^{\circ} \mathrm{C}$ and $\varphi=0 \% \rightarrow 54 \%$ 


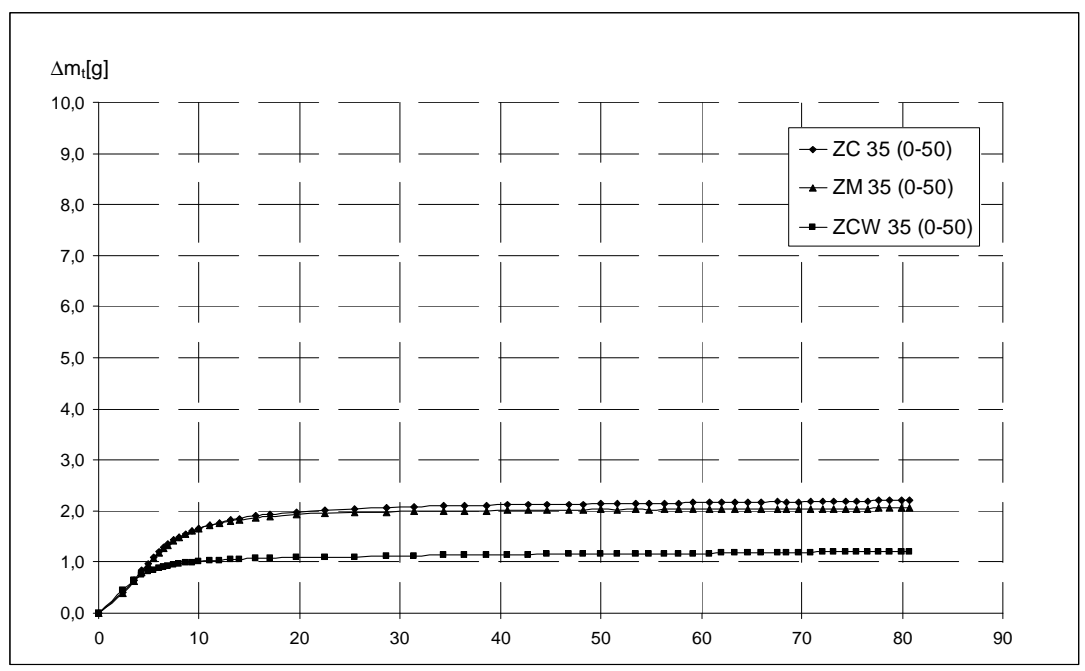

Rys. 5. Wypadkowe przebiegi $\Delta m_{t}=\mathrm{f}(\sqrt{ } t)$ dla zaprawy cementowej, zaprawy modyfikowanej oraz cementowo-wapiennej w $T=35^{\circ} \mathrm{C}$ oraz $\varphi=0 \% \rightarrow 50 \%$

Fig. 5. Graph of function $\Delta m_{t}=\mathrm{f}(\sqrt{ } t)$ for cement mortar, modified mortar and cementlime mortar at $T=35^{\circ} \mathrm{C}$ and $\varphi=0 \% \rightarrow 50 \%$

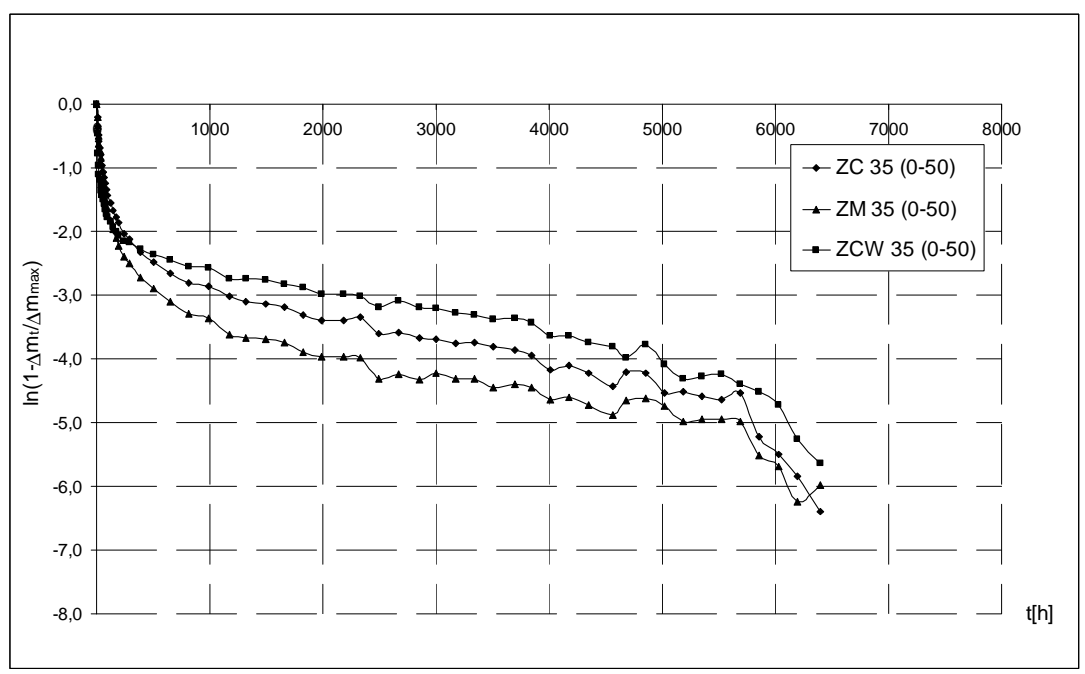

Rys. 6. Wypadkowe przebiegi $\ln \left(1-\Delta m_{t} / \Delta m_{\max }\right)=\mathrm{f}(t)$ dla zaprawy cementowej, zaprawy modyfikowanej oraz cementowo-wapiennej w $T=35^{\circ} \mathrm{C}$ oraz $\varphi=0 \% \rightarrow 50 \%$

Fig. 6. Graph of function $\ln \left(1-\Delta m_{t} / \Delta m_{\max }\right)=\mathrm{f}(t)$ for cement mortar, modified mortar and cement-lime mortar at $T=35^{\circ} \mathrm{C}$ and $\varphi=0 \% \rightarrow 50 \%$ 
Sporządzone wykresy z założenia służą do wyznaczania współczynników kierunkowych $a_{\sqrt{ }}$ oraz $a_{\mathrm{ln}}$, przypisywanych do prostoliniowych odcinków w przebiegach funkcyjnych $\Delta m_{t}=\mathrm{f}(\sqrt{ } t)$ oraz $\ln \left(1-\Delta m_{t} / \Delta m_{\max }\right)=\mathrm{f}(t)$. Współczynniki $a_{\sqrt{ }}$ oraz $a_{\mathrm{ln}}$ stanowią podstawę dalszego obliczania współczynników dyfuzji $D_{m}(\sqrt{ } t)$ oraz $D_{m}(\ln )$ odpowiadających danej próbce, badanej sorpcyjnie w danym cyklu o ściśle zdefiniowanych uwarunkowaniach cieplno-wilgotnościowych.

W tabeli 1 zestawiono współczynniki dyfuzji poszczególnych zapraw wyznaczone w $T=5,20,35^{\circ} \mathrm{C}$ w kolejno testowanych zakresach wilgotności.

Podane w tabeli współczynniki $D_{m}(\sqrt{ } t)$ oraz $D_{m}(\ln )$ stanowią średnie wartości obliczone na podstawie wyników składowych uzyskanych daną metodą $\mathrm{z}$ trzech próbek badanych $\mathrm{w}$ danym cyklu.

Tablica 1. Zestawienie wypadkowych wartości $D_{m}$ wyznaczonych dla testowanych zapraw w pomiarach sorpcyjnych za pomocą metody typu $\sqrt{t}$ oraz metody logarytmicznej.

Table 1 . Average values of mass diffusivity $D_{m}$ of tested mortars found in the sorption measurements by $\sqrt{ } t$-type method and logarithmic method.

\begin{tabular}{|c|c|c|c|c|c|c|c|}
\hline \multirow{2}{*}{$\begin{array}{c}\text { Za- } \\
\text { prawa }\end{array}$} & \multirow{2}{*}{$\begin{array}{c}\text { Zakres } \\
\Delta \varphi[\%]\end{array}$} & \multicolumn{2}{|c|}{ Temperatura $5^{\circ} \mathrm{C}$} & \multicolumn{2}{|c|}{ Temperatura $20^{\circ} \mathrm{C}$} & \multicolumn{2}{|c|}{ Temperatura $35^{\circ} \mathrm{C}$} \\
\hline & & $D_{m}(\sqrt{ } t)$ & $D_{m}(\ln )$ & $D_{m}(\sqrt{ } t)$ & $D_{m}(\mathbf{l n})$ & $D_{m}(\sqrt{ } t)$ & $D_{m}(\ln )$ \\
\hline \multirow{6}{*}{$\mathrm{ZC}$} & $0 \rightarrow 11$ & $8,30 \mathrm{E}-09$ & $8,24 \mathrm{E}-09$ & $3,84 \mathrm{E}-08$ & 3,81E-08 & $6,45 \mathrm{E}-08$ & $6,11 \mathrm{E}-08$ \\
\hline & $0 \rightarrow 32 \div 34$ & $1,85 \mathrm{E}-08$ & $1,75 \mathrm{E}-08$ & $6,36 \mathrm{E}-08$ & $6,15 \mathrm{E}-08$ & $18,33 \mathrm{E}-08$ & $17,94 \mathrm{E}-08$ \\
\hline & $0 \rightarrow 50 \div 59$ & 2,62E-08 & 2,52E-08 & $6,96 \mathrm{E}-08$ & 6,76E-08 & $19,99 \mathrm{E}-08$ & $20,11 \mathrm{E}-08$ \\
\hline & $0 \rightarrow 75 \div 76$ & $1,82 \mathrm{E}-08$ & $1,78 \mathrm{E}-08$ & $5,41 \mathrm{E}-08$ & $5,12 \mathrm{E}-08$ & $15,13 \mathrm{E}-08$ & $15,28 \mathrm{E}-08$ \\
\hline & $0 \rightarrow 83 \div 88$ & $1,37 \mathrm{E}-08$ & $1,34 \mathrm{E}-08$ & $3,37 \mathrm{E}-08$ & $3,36 \mathrm{E}-08$ & $8,71 \mathrm{E}-08$ & $9,03 \mathrm{E}-08$ \\
\hline & $0 \rightarrow 96 \div 98$ & $8,32 \mathrm{E}-09$ & 9,06E-09 & $1,91 \mathrm{E}-08$ & $1,77 \mathrm{E}-08$ & 7,07E-08 & 7,22E-08 \\
\hline \multirow{6}{*}{$\mathrm{ZM}$} & $0 \rightarrow 11$ & $2,00 \mathrm{E}-08$ & $2,01 \mathrm{E}-08$ & $3,00 \mathrm{E}-08$ & $3,00 \mathrm{E}-08$ & $8,05 \mathrm{E}-08$ & $8,14 \mathrm{E}-08$ \\
\hline & $0 \rightarrow 32 \div 34$ & 2,85E-08 & 2,86E-08 & 7,70E-08 & 7,67E-08 & $19,86 \mathrm{E}-08$ & $19,50 \mathrm{E}-08$ \\
\hline & $0 \rightarrow 50 \div 59$ & 3,39E-08 & $3,48 \mathrm{E}-08$ & $9,84 \mathrm{E}-08$ & $9,83 \mathrm{E}-08$ & $20,23 \mathrm{E}-08$ & $19,83 \mathrm{E}-08$ \\
\hline & $0 \rightarrow 75 \div 76$ & 3,61E-08 & $3,57 \mathrm{E}-08$ & $6,78 \mathrm{E}-08$ & $6,75 \mathrm{E}-08$ & $17,67 \mathrm{E}-08$ & 17,39E-08 \\
\hline & $0 \rightarrow 83 \div 88$ & $1,56 \mathrm{E}-08$ & $1,54 \mathrm{E}-08$ & $4,25 \mathrm{E}-08$ & 4,27E-08 & $12,56 \mathrm{E}-08$ & $12,61 \mathrm{E}-08$ \\
\hline & $0 \rightarrow 96 \div 98$ & 9,99E-09 & 9,96E-09 & $2,02 \mathrm{E}-08$ & $2,02 \mathrm{E}-08$ & $7,05 \mathrm{E}-08$ & 7,11E-08 \\
\hline \multirow{6}{*}{$\mathrm{ZCW}$} & $0 \rightarrow 11$ & 5,63E-08 & $5,37 \mathrm{E}-08$ & $10,68 \mathrm{E}-08$ & $10,47 \mathrm{E}-08$ & 9,68E-08 & $9,91 \mathrm{E}-08$ \\
\hline & $0 \rightarrow 32 \div 34$ & 7,31E-08 & $7,25 \mathrm{E}-08$ & $16,20 \mathrm{E}-08$ & $15,37 \mathrm{E}-08$ & $26,75 \mathrm{E}-08$ & $27,30 \mathrm{E}-08$ \\
\hline & $0 \rightarrow 50 \div 59$ & $10,78 \mathrm{E}-08$ & $10,79 \mathrm{E}-08$ & 26,67E-08 & $24,36 \mathrm{E}-08$ & $39,26 \mathrm{E}-08$ & 37,91E-08 \\
\hline & $0 \rightarrow 75 \div 76$ & 3,99E-08 & 3,93E-08 & $9,17 \mathrm{E}-08$ & $9,16 \mathrm{E}-08$ & $21,25 \mathrm{E}-08$ & 21,62E-08 \\
\hline & $0 \rightarrow 83 \div 88$ & 2,25E-08 & 2,24E-08 & 9,64E-08 & $9,62 \mathrm{E}-08$ & $18,33 \mathrm{E}-08$ & $18,38 \mathrm{E}-08$ \\
\hline & $0 \rightarrow 96 \div 98$ & 4,70E-09 & 4,68E-09 & $2,28 \mathrm{E}-08$ & $2,30 \mathrm{E}-08$ & $8,05 \mathrm{E}-08$ & $7,76 \mathrm{E}-08$ \\
\hline
\end{tabular}




\section{Podsumowanie}

Zrealizowane badania sorpcyjne, którymi objęto trzy materiały kapilarnoporowate, dowodzą, że dwie testowane procedury sorpcyjne w przypadku takich materiałów jak ZC, ZM i ZCW cechują się dobrym odtworzeniem założeń teoretycznych $\mathrm{w}$ przebiegach funkcyjnych $\Delta m_{t}=\mathrm{f}(\sqrt{ } t)$ oraz $\ln \left(1-\Delta m_{t} / \Delta m_{\max }\right)=$ $\mathrm{f}(t)$ i w konsekwencji gwarantują poprawne określenie wartości $D_{m}(\sqrt{ } t)$ oraz $D_{m}(\ln )$, na podstawie wyznaczonych wcześniej współczynników kierunkowych $a_{\sqrt{ } t}$ oraz $a_{\mathrm{ln}}$. Obydwie procedury obliczeniowe wykorzystane do wyznaczenia $D_{m}$ dostarczyły zbliżonych wartości tego współczynnika.

Przeprowadzone badania pozwalają ponadto ocenić, jak wpływa na wartość współczynnika dyfuzji zmieniający się zakres wilgotności. Analizując współczynnik $D_{m}$ z uwagi na zmieniającą się wilgotność można zaobserwować jednoznaczną tendencję obserwowaną w każdej temperaturze i dotyczącą każdej z badanych zapraw. Stwierdza się mianowicie wzrost wartości $D_{m}$ wraz ze zwiększaniem się wilgotności względnej do poziomu 50\%. W miarę dalszego wzrostu wilgotności obserwuje się spadek $D_{m}$. Przy badaniach prowadzonych w najszerszym zakresie, tj. przy $\varphi \approx 96 \%$ współczynniki $D_{m}$ osiągają wartość minimalną, zbliżoną do tej wyznaczanej w zakresie najniższych wilgotności.

Zestawione w tabeli 1 dane pozwalają także na ilościową ocenę wpływu temperatury w poszczególnych analizowanych przypadkach. Stwierdza się bardzo znaczące oddziaływanie tego czynnika na wartości $D_{m}$. Im wyższa temperatura tym wyższa wartość współczynnika dyfuzji. W zdecydowanej większości przypadków odnotowano wzrosty sięgające kilkuset procent.

Wobec uzyskiwania we wszystkich cyklach zbliżonych wartości współczynników $D_{m}(\sqrt{ } t)$ oraz $D_{m}(\ln )$ w przypadku każdej z zapraw - można uznać obydwie procedury za porównywalne i kwalifikujące się do wyznaczania $D_{m}$ z niestacjonarnych procesów sorpcji.

\section{Literatura}

[1] Garbalińska H.: Izotermiczne współczynniki transportu wilgoci porowatego materiału budowlanego. Prace Naukowe Politechniki Szczecińskiej Nr 571. Szczecin 2002.

[2] Garbalińska H.: Measurement of the mass diffusivity in cement mortar: use of initial rates of water absorption. International Journal of Heat and Mass Transfer 2002 Vol. 45 No. 6, s. 1353-1357.

[3] Garbalińska H.: Application of the logarithmic procedure to absorption measurements of mass diffusivity for cement mortars. Research Journal Heat and Mass Transfer 40, wyd. Springer-Verlag 2004, s. 963-972.

[4] Garbalińska H.: Application of $\sqrt{t}$-type, logarithmic and half-time methods in desorptive measurements of diffusivity in narrow humidity ranges. Cement and Concrete Research 36 (2006), s. 1294-1303.

[5] Garbalińska H., Garbasz B.: Wąsko-przedziałowe pomiary sorpcyjne współczynnika dyfuzji cegły ceramicznej, silikatowej i betonu komórkowego. XI Polska Konfe- 
rencja Naukowo-Techniczna Fizyka budowli w Teorii i Praktyce, Czasopismo Naukowe tom II, Sekcja Fizyki Budowli Komitetu Inżynierii Lądowej i Wodnej PAN, Łódź 2007, s. 35-40.

[6] Krus M.: Feuchtetransport- und Speicherkoeffizienten poröser mineralischer Baustoffe. Theoretische Grundlagen und neue Meßtechniken. Dissertation, Universität Stuttgart 1995.

[7] Künzel H. M., Kiessl K.: Bestimmung des Wasserdampfdiffusionswiderstandes von mineralischen Baustoffen aus Sorptionsversuchen. Bauphysik 1990 Jg. 12 H. 5, s. $140-150$.

\section{SORPTION MEASUREMENTS FOR DEFINING THE MOISTURE DIFFUSION COEFFICIENT OF DIFFERENT KIND OF MORTARS}

\section{S u m m a r y}

The paper presents possibilities of application of non-stationary sorption measurements to determine the diffusion coefficient $D_{m}$ of porous building materials. The research covers three different mortars: cement mortar, cement-lime mortar and modified mortar. The experiment was conducted in 18 different types of climate, at the three following temperatures: $5^{\circ} \mathrm{C}, 20^{\circ} \mathrm{C}$ and $35^{\circ} \mathrm{C}$, and at six relative humidity levels $\varphi$. Basing of the results of sorption measurements, values of diffusion coefficient $D_{m}$ were calculated for different mortars, and the particular values obtained referred to various temperatures and various levels of sorption moisture. Calculations of coefficient $D_{m}$ shown in this paper were based on $\sqrt{ }_{t}$-type and logarithmic-type procedures. The obtained results allowed to evaluation the usability of two procedures for the tested materials. In all cycles and for each of the mortars, similar values of coefficients $D_{m}(\sqrt{ } t)$ and $D_{m}(\ln )$ were observed, which enables to recommend the both procedures as comparable ones. Moreover, the research allowed to assess the influence of moisture content on diffusion coefficient values. A clear tendency appeared for each temperature and each of the mortars researched. There was observed increase of the $D_{m}$ value together with the rise of relative humidity up to the level of $50 \%$. For this level of moisture in the material the diffusion coefficient reached the maximum value. After that, the value of the coefficient was gradually decreasing together with increase of moisture. It was concluded that in the broadest humidity range, i.e. at $\varphi \approx 96 \%$, diffusion coefficients reach the minimum values referring to the range of lowest level of moisture. The conducted research allowed to assess not only the influence of moisture but the impact of temperature as well. The both methods showed considerable influence of this factor on $D_{m}$ values.

Keywords: sorption, moisture diffusion, diffusion coefficient, mortar, porous material

Przestano do redakcji: 01.12.2014 r.

Przyjęto do druku: 22.06.2015 r.

DOI:10.7862/rb.2015.39 